\title{
Hyperurikämie
}

\section{Mehr als nur ein dicker Großzeh}

— Vorurteile halten sich meist hartnäckig. So auch, dass Gicht in der Regel selbst verschuldet ist. Weniger Fleisch, weniger Alkohol, heißt es oft nach einem Gichtanfall. Doch warum bekommt der eine Mensch eine Gichtattacke, der andere jedoch nicht? Obwohl der doch mehr Steaks gegessen und mehr Bier getrunken hat? Die Gicht ist eine symptomatische Stoffwechselerkrankung mit genetischer Disposition, lautet eine der Kernbotschaften einer interaktiven Fortbildung* zur symptomatischen Hyperurikämie.

\section{Online informieren}

In dem rund zehnminütigen Modul des Unternehmens Berlin-Chemie wird auch auf den Purinstoffwechsel und die der

* www.fokus-harnsaeure.de, das Log-In kann über den Springer-Medizin-Account erfolgen
Gicht zugrundeliegende gestörte renale Uratclearance eingegangen. Verdeutlicht wird darüber hinaus, dass die Gicht eine chronische Systemerkrankung ist, die nicht nur Gelenke, sondern auch Herz, Niere und Auge treffen kann. Gicht erhöht zudem das Risiko, eine Nierenerkrankung oder einen Diabetes mellitus zu entwickeln, und auch das Mortalitätsrisiko.

Diese Folgen der verminderten Uratclearance zu verhindern, ist das Therapieziel bei symptomatischer Hyperurikämie, heißt es in dem produktneutralen Modul. Eine Ernährungsumstellung kann den Harnsäurewert im Serum meist nur um $1 \mathrm{mg} / \mathrm{dl}$ senken. Um den Zielwert von unter $6 \mathrm{mg} / \mathrm{ml}$ zu erreichen, wird meist eine Pharmakotherapie nötig. Dass sich eine konsequente Therapie lohnt, ist eine weitere Kernbotschaft: Denn Ablagerungen

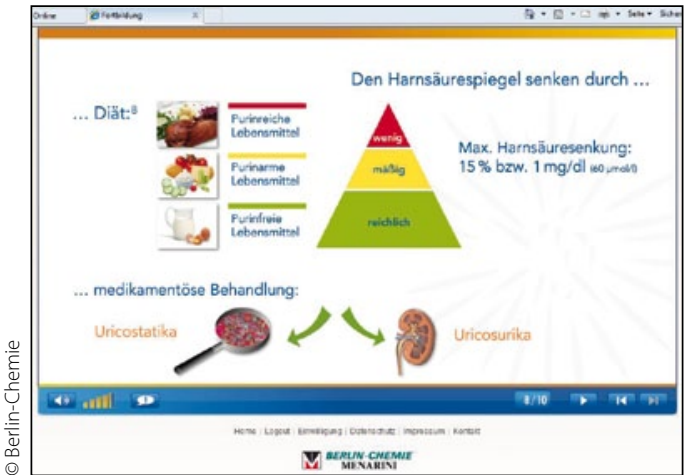

Ansprechend aufbereitet und informativ das Modul zur Hyperurikämie.

von Uratkristallen in Organen und Gelenken gehen dann wieder in Lösung.

- Dr. Michael Hubert

Quelle: eDetailing des Unternehmens BerlinChemie
— Viele Ärzte vermeiden es, Anticholinergika bei älteren Menschen mit überaktiver Blase (overactive bladder, OAB) einzusetzen. Größter Vorbehalt: Die Wirkstoffe könnten die Kognition beeinträchtigen. Eine aktuelle Studie von Adrian Wagg, Geria-

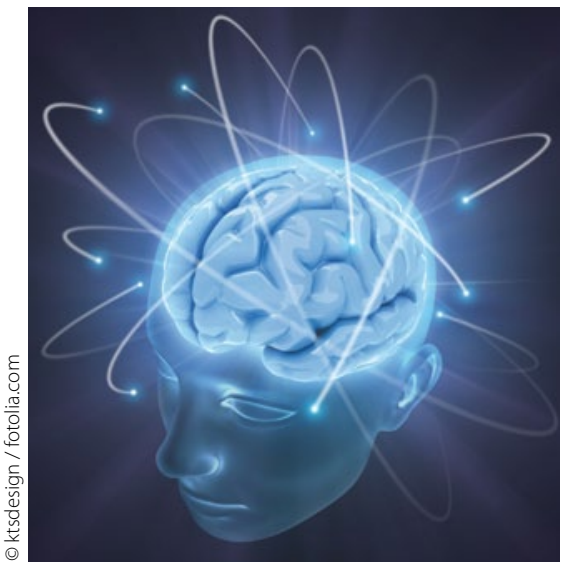

Die geistige Leistungsfähigkeit erhalten - das geht auch unter anticholinergischer Therapie. ter der University of Alberta in Edmonton, Canada, widerlegt diese Vorurteile: Wagg und seine Kollegen konnten in der SENIOR-Studie bei 26 Patienten (medianes Alter: 76 Jahre) mit milder eingeschränkter Kognition zeigen, dass keine statistisch signifikanten Unterschiede bei den fünf getesteten Kognitionsparametern zwischen Solifenacin (Vesikur ${ }^{\circledR}$ ) und Placebo auftraten, berichtete Prof. Ruth KirschnerHermanns, Bonn, im Gespräch mit der Ärzte Zeitung.

Spätestens seit der EPIC-Studie aus dem Jahre 2005 weiß man, dass die OAB eine der häufigsten Blasenfunktionsstörungen ist, die mit dem Alter deutlich zunimmt. Typische Symptome gemäß International Continence Society (ICS) sind überfallartiger Harndrang, Pollakisurie und Nykturie. Gerade der nächtliche Harndrang kann bei Älteren zur erhöhten Komorbidität führen, indem er beispielsweise Stürze begünstigt.
Neben nicht medikamentösen Therapiemöglichkeiten wie Blasen- und Toilettentraining gelten Anticholinergika nach den Leitlinien nationaler und internationaler Fachgesellschaften als Therapeutika der Wahl mit hohem Evidenzlevel bei der OAB. „Mit dem richtigen Augenmaß auf die besondere Situation des Älterer muss der mögliche Nutzen einer anticholinergen Therapie abgeschätzt werden", so Kirschner-Hermanns.

"Anticholinergika stellen eine hoch wirksame Therapie dar", so die Expertin. Sie reduzieren die Detrusorkontraktilität, verringern den Detrusordruck und führen zu einer gesteigerten Blasenkapazität. Dadurch bessert sich die Drangsymptomatik, sodass Inkontinenzepisoden und die damit verbundenen Folgeereignisse seltener auftreten.

- Constanze Löffler

Quelle: Interview mit Frau Professor Ruth Kirschner-Hermanns 